Thesis summary

\title{
ANALYSIS OF VARIATION IN A LOCAL POPULATION OF PERENNIAL RYEGRASS (LOLIUM PERENNE L.)
}

\author{
(Postgraduate Diploma in Agric. Science, Massey University)
}

\section{F. R. Duder}

Samples of perennial ryegrass plants were taken 'from nine sites on one farm at Mangere. Single tillers were planted out as spaced plants in contiguous rows in a trial site on the same farm.

The plants were studied for two years. During this time, observations on leaf growth and selected morphological and physiological characters were made under environmental conditions representing normal, farming practice. The morphological characters observed were tiller angle, tiller density and leaf width. Plants were observed for the time of seed head appearance (= heading) and for the incidence of rust (Puccinia spp.) .

A series of leaf growth scores was made over a thirteen-month period from February 1974 to mid-March 1975. Significant differences between individual populations or groups of populations were recorded. These differences were more apparent as the experiment proceeded, differences being most noticeable over the dry spring, summer and autumn periods.

Some populations showed consistent trends in their rankings within and amongst seasons. Other populations were inconsistent in rankings both within and amongst seasons. There was no evidence to suggest periodicity in leaf growth over the thriteenmonth period.

There was no consistency in the two significant tiller angle observations. Populations appeared to change in their plant type (namely, prostrate or erect) with time. Possible reasons for the lack of consistency were discussed, including the technique used, and the influence of reproductive development on plant type classification.

There were significant differences in tiller density between broad groupings of populations. However, there was a lack of consistency in the rankings of populations over consecutive observations. No single population was significantly different in leaf width. This suggested, on a population basis, that leaf width may not be a useful guide to field identification of Mangere cultivars.

A high incidence of rust infestation (Puccinia graminis) was observed in the very dry and hot conditions of the first summer. 
There was little difference in the susceptibility between popula-, tions during the most severe infestation. The effects of rust on perennial ryegrass and its implication to pasture production and quality in summer and autumn were reviewed briefly.

Significant differences in the dates of heading across several populations were recorded. Significantly later-heading populations were of interest in relation to their subsequent summer leaf growth. The relationship of heading date with summer regrowth was discussed. The implications of extended summer growth observed in the Mangere "ecotype" for breeding a late-heading perennial ryegrass were suggested. 